\title{
Synergistic effects of valproic acid and arsenic trioxide on RPMI8226 cells in vitro and the possible underlying mechanisms
}

\author{
XIAONING WANG and MEI ZHANG \\ Department of Hematology, The First Affiliated Hospital, School of Medicine, \\ Xi'an Jiaotong University, Xi'an, Shaanxi 710061, P.R. China
}

Received May 30, 2014; Accepted February 27, 2015

DOI: $10.3892 / \mathrm{mmr} .2015 .3519$

\begin{abstract}
The aim of the present study was to investigate the synergistic effects of valproic acid (VPA) and arsenic trioxide (ATO) on the proliferation of RPMI8226 cells and the possible underlying mechanisms. Cell apoptosis was assessed by flow cytometry. The mRNA expression levels were analyzed by semi-quantitative polymerase chain reaction, and the protein expression levels were analyzed by western blotting. The histone acetylation and methylation states of the gene promoters were detected using a chromatin immunoprecipitation technique. The apoptotic rates of the RPMI8226 cells in the combined drug groups were significantly increased compared with those of the single drug groups $(\mathrm{P}<0.05)$. The mRNA and protein expression levels of $\mathrm{Bcl}-2$ and the expression levels of $\mathrm{HDAC} 1 \mathrm{mRNA}$ and $\mathrm{H} 3 \mathrm{~K} 9 \mathrm{me} 2$ protein decreased significantly in the combined groups compared with the single drug groups. The mRNA and protein expression levels of Bax, Caspase 8, Caspase 9 and LSD1, and the protein expression of acetylated H3 increased significantly in the combination groups compared with the single drug groups. Histone methylation and acetylation of the Bcl-2 and bax gene promoters were increased in the combination groups compared with the single drug groups. VPA and ATO had synergistic effects on the proliferation of RPMI8226 cells, which may have been associated with the decreased expression of $\mathrm{Bcl}-2$ and the increased expression levels of Bcl-2-associated X protein, Caspase 8 and Caspase 9. Therefore, the expression levels of the Bcl-2 gene family may have been regulated by the levels of gene promoter methylation and acetylation.
\end{abstract}

Correspondence to: Mrs. Mei Zhang, Department of Hematology, The First Affiliated Hospital, School of Medicine, Xi'an Jiaotong University, 277 Yanta West Road, Xi'an, Shaanxi 710061, P.R. China E-mail: zhangmeimedmail@163.com

Key words: valproic acid, arsenic trioxide, multiple myeloma, synergistic effect, chromatin immunoprecipitation

\section{Introduction}

Multiple myeloma (MM) is a plasma cell disorder, characterized by anemia, renal disease, lytic bone disease, and immune dysfunction. MM is one of the most common types of hematological malignancy in China (1). Although currently approved treatments for newly diagnosed MM, including high-dose chemotherapy followed by autologous transplantation, and novel drugs, including proteasome inhibitors and immunomodulatory agents (IMiDs), have led to increased survival rates, the majority of patients will eventually relapse and become refractory to treatment (2). Therefore, patients with relapsed or refractory MM have an unmet requirement for safe and efficacious novel therapies.

Arsenic trioxide (ATO) has been suggested as an option for the treatment of relapsing or refractory MM. In vitro, $\mathrm{ATO}$ has been found to induced myeloma cell apoptosis, and monotherapy with ATO results in partial response rates between 0 and $17 \%$, and minimal responses between 7 and $33 \%$, resulting in mean overall response rates of $30 \%$ for treatment of myeloma (3-5).

In order to improve the treatment response rates in patients with MM, ATO has been combined with other novel drugs, including proteasome inhibitors, IMiDs and dexamethsone, for the treatment of MM. The overall response rates in these combined regimens vary widely between 12 and $100 \%$ (6-8). It is necessary to identify novel combinations of ATO with other drugs, to offer novel mechanisms for treating MM.

The observation that histone deacetylases (HDAC) may be involved in various types of hematologic malignancy has led to the development of HDAC inhibitors as potential antitumor agents (9). VPA, as one type of HDACI, has the unique advantage of oral dosage, and can achieve its effective concentration with low toxicity, providing a useful tool for investigating the mechanism of the HDAC inhibitor. The present study aimed to investigate the synergistic effects of VPA and ATO and its underlying mechanism.

\section{Materials and methods}

Cells and reagents. The RPMI8226 myeloma cell line was obtained from the Shanghai Cell Bank of the Chinese Academy of Sciences(Shanghai, China). The cells were cultured in RPMI-1640 medium, supplemented with 
$10 \%$ heat-inactivated fetal bovine serum (FBS; HyClone, Beijing, China), $100 \mathrm{U} / \mathrm{ml}$ penicillin, $100 \mathrm{mg} / \mathrm{ml}$ streptomycin and $2 \mathrm{mmol} / \mathrm{l}$ glutamine (North China Pharmaceutical Co., Ltd., Shijiazhuang, China) at $37^{\circ} \mathrm{C}$ in humidified air containing $5 \% \mathrm{CO}_{2}$. The culture medium was replaced every 3 days. ATO (Harbin Yida Pharmaceutical Co, Ltd., Harbin, China) was stored at room temperature, VPA powder (Dalian Meilun Biological Technology Co, Ltd., Dalian, China) was dissolved in $0.9 \% \mathrm{NaCl}$ to produce a $60 \mathrm{mM}$ stock solution. The VPA solution was diluted in $0.9 \% \mathrm{NaCl}$ just prior to use. All experiments were performed using cells in the logarithmic phase.

The rabbit anti-human monoclonal Bcl-2, Bax, Caspase 8, Caspase 9, LSD1 and JMJD2B antibodies, and rabbit anti-human polyclonal acetylated-H3 and H3K9me2 antibodies were purchased from Cell Signaling Technology Inc. (Danvers, MA, USA), and mouse anti-human monoclonal $\beta$-actin antobidy was purchased from Beijing Sinopept Biotechnology, Co., Ltd. (Beijing, China). The chromatin immunoprecipitation (CHIP) assay kit was purchased from EMD Millipore (Billerica, MA, USA).

Cell viability assays. To evaluate the growth inhibitory effect of VPA and ATO on the myeloma cells, a Cell Counting kit (CCK)-8 colorimetric assay was used, according to the manufacturer's instructions. Briefly, the RPMI8226 cells were inoculated into each well of 96 -well culture plates, at a density of $1 \times 10^{6} \mathrm{cells} / 1$ with $100 \mu \mathrm{l}$ for each well, in the presence of VPA $(1$ or $5 \mathrm{mmol} / \mathrm{l})$ or ATO $(4 \mu \mathrm{mmol} / \mathrm{l})$ or the two drugs in combination, at the same concentrations, for 24,48 and $72 \mathrm{~h}$ at $37^{\circ} \mathrm{C}$ in a $5 \% \mathrm{CO}_{2}$ incubator. CCK-8 solution $(10 \mu \mathrm{l})$ was added to each well of the plate during the last $2 \mathrm{~h}$ of incubation. This was followed by measurement of absorbance at a wavelength of $490 \mathrm{~nm}$ using an absorbance microplate reader (ELx808, Bio-Tek, Winooski, VT, USA). Interactions between the two drugs were determined using the gold (Zheng Jun) formula (10). Q = E (a+b)/(Ea+Eb-Ea x Eb), where Ea was the cell inhibition rate of RPMI8226 cells treated with ATO, Eb was the cell inhibition rate of RPMI8226 cells treated with VPA, and E $(a+b)$ was the cell inhibition rate of RPMI8226 cells treated with ATO combined with VPA. When $\mathrm{Q}<0.85$, the combination of the two drugs had an antagonistic effect; when $\mathrm{Q}$ was between 0.85 and 1.15 , the combination of the two drugs had a simple additive effect; and when $\mathrm{Q}>1.15$, the combination of the two drugs had a synergistic effect.

Observation of cell morphology. The RPMI8226 cells were cultured in $25 \mathrm{ml}$ culture flasks at a concentration of $5 \times 10^{4} / 1$ ( $5 \mathrm{ml}$ in each flask). The subgroups and treatment methods used were the same as those used for the CCK- 8 assay. The cells were harvested after 2 days and were observed using inverted microscopy (CX31; Olympus Corporation, Tokyo, Japan).

Staining with annexin V-fluorescein isothiocyanatelpropidium iodide (PI) and detection of apoptosis. Apoptosis was determined by staining the cells with annexin V-FITC/PI (Jiamay Biotechnology Co., Ltd., Beijing, China), according to the manufacturer's instructions. The stained cells were then analyzed by flow cytometry (FACSCanto; BD
Biosciences, Franklin Lakes, NJ, USA). The rates of apoptosis were quantified using FlowJo software (version 7.6; Tree star, Inc., Ashland, OR, USA).

Semi-quantitative PCR analysis. The total RNA were extracted with RNA fast200 (Fastagen Biotechnology Co.,Ltd.,Shanghai, China). The RNA content and purity were measured using a DU-600 spectrophotometer (Beckman Coulter, Fullerton, CA, USA). The required A260/A280 ratio was 1.8-2.0. The RNA $(1 \mu \mathrm{g})$ was reverse transcribed to cDNA using oligo (dT) 18 primers and M-MIV reverse transcriptase (Thermo Fisher Scientific, Pittsburgh, PA, USA). The qPCR analyses for the mRNA transcripts were performed using the following primers: Bcl-2, forward 5'-GAACTGGGGGAGGATTGTGG-3' and reverse 5'-CCGGTTCAGGTACTCAGTCA-3; Bax, forward 5'-AAGCTGAGCGAGTGTCTCCGGCG-3' and reverse 5'-GCCACAAAGATGGTCACTGTCTGCC-3'; Caspase 8, forward 5'-CTGGGAAGGATCGACGATATA-3' and reverse 5'-CATGTCCTGCATTTTGATGG-3'; Caspase 9, forward 5'-AGCCAGATGCTGTCCCATAC-3' and reverse 5'-CAGGAGACAAAACCTGGGAA-3'; LSD1, forward 5'-GCCAGGCATTGGAAGTTGT-3' and reverse 5'-TGACCGCCCTATGCAAGG-3'; and HDAC1, forward 5'-GCTCCATCCGTCCAGATAACA-3' and reverse 5'-TGCC ACAGAACCACCAGTAGA (Dingguo Changsheng Co., Ltd., Beijing, China). The qPCR was performed using the following cycles: 35 cycles at $94^{\circ} \mathrm{C} 45 \mathrm{sec}, 50^{\circ} \mathrm{C}$ for $45 \mathrm{sec}$, and $72^{\circ} \mathrm{C}$ for $60 \mathrm{sec}$. The qPCR products of Bcl-2, Bax, Caspase 8, Caspase 9, LSD1 and HDAC1 (124, 284, 117, 201, 234 and $128 \mathrm{bp}$, respectively) were verified by $1.2 \%$ agarose gel electrophoresis stained by ethidium bromide (GE Healthcare Life Sciences, Piscataway, NJ, USA). The mRNA expression of $\beta$-actin was used as control.

Western blotting. The total protein was isolated from the cell pellet using radioimmunoprecipitation buffer (Beyotime Institute of Biotechnology, Shanghai, China), and quantified using a Bicinchoninic Acid kit (Beyotime Biotechnology, Shanghai, China). A total of $35 \mu \mathrm{g}$ total protein from the cell lysate was then separated on $12 \%$ SDS-polyacrylamide gels and transferred onto cellulose acetate membranes (Beyotime Biotechnology) at a constant current of $320 \mathrm{~mA}$ for $1 \mathrm{~h}$. The membranes were blocked with 5\% bovine serum albumin (HyClone) in Tris-buffered saline with $0.5 \mathrm{ml} / 1$ Tween-20 (TBS-T) and probed overnight at $4^{\circ} \mathrm{C}$ with 1:1,000 dilutions of Bcl-2, Bax, Caspase 8, Caspase 9, LSD1, acetylated H3 and H3K9me2 primary antibodies. The membranes were then washed five times with TBS-T and incubated with a 1:3,000 dilution of anti-rabbit horesreadish peroxidase-conjugated secondary antibody for $2 \mathrm{~h}$ at room temperature. The membranes were washed again five times with TBS-T, and the proteins were visualized using enhanced chemuluminescence (EMD Millipore). $\beta$-actin was used as an internal control.

Chromatin immunoprecipitation. The level of histone methylation of the Bcl-2 gene promoter and the acetylation level of the Bax gene promoter were determined using a CHIP assay (EMD Millipore), according to the manufacturer's instructions. The RPMI8226 cells were inoculated into each well of 6-well culture plates, at a concentration 
Table I. Acetylation level of the Bax gene promoter and methylation level of the Bcl-2gene promoter.

Group $A B a x / A$ positive control

$A B c l-2 / A$ positive control

Control group
VPA $1 \mathrm{mmol} / 1$
VPA $5 \mathrm{mmol} / 1$
ATO $4 \mu \mathrm{mol} / 1$
VPA $1 \mathrm{mmol} / 1+$ ATO $4 \mu \mathrm{mol} / 1$
VPA $5 \mathrm{mmol} / 1+$ ATO $4 \mu \mathrm{mol} / 1$

$0.31 \pm 0.01$
$0.33 \pm 0.03$
$0.30 \pm 0.02$
$0.31 \pm 0.05$
$0.68 \pm 0.02^{\mathrm{a}, \mathrm{b}}$
$0.84 \pm 0.05^{\mathrm{a}, \mathrm{b}}$

$0.23 \pm 0.02$

$0.25 \pm 0.01$

$0.30 \pm 0.03$

$0.37 \pm 0.02$

$0.52 \pm 0.05^{\mathrm{a}, \mathrm{b}}$

$0.68 \pm 0.04^{\mathrm{a}, \mathrm{b}}$

${ }^{a} \mathrm{P}<0.05$, compared with the untreated control group. ${ }^{\mathrm{b}} \mathrm{P}<0.05$, compared with the single drug groups. A, acetylation; VPA, valproic acid; ATO, arsenic trioxide; Bcl-2, B-cell lymphoma 2; Bax, Bcl-2-associated X protein. Anti-RNA polymerase antibody was used as a positive control.

of $1 \times 10^{6} \mathrm{cells} / \mathrm{l}$, and treated with VPA or ATO alone or with the two in combination, for $48 \mathrm{~h}$ at $37^{\circ} \mathrm{C}$ in a $5 \% \mathrm{CO}_{2}$ incubator. The histones were cross-linked to DNA by adding formaldehyde (Xian Chemical Reagent Factory, Xian, China) directly to the culture medium to a final concentration of $1 \%$, followed by incubation for $10 \mathrm{~min}$ at $37^{\circ} \mathrm{C}$, and the addition of $0.125 \mathrm{M}$ glycine (Amresco, LLC, Solon, $\mathrm{OH}, \mathrm{USA}$ ) to terminate the cross-linking. The cells were washed twice using cold PBS, containing protease inhibitors (Roche Diagnostics, Basel, Switzerland), and centrifuged for $4 \mathrm{~min}$ at $2,000 \mathrm{x} \mathrm{g}$ at $4^{\circ} \mathrm{C}$, followed by resuspending the cells in SDS lysis buffer $\left(1 \times 10^{6}\right.$ cells $/ 200 \mu 1$; Amresco, LLC). Sonicate lysate (200 $\mu$; EMD Millipore) was used to shear the DNA to lengths between 200 and 1,000 bp. The sonicated cell supernatant was diluted 10-fold in CHIP dilution buffer (EMD Millipore), and primary antibody, including anti RNA polymerase antibody as positive control, normal rabbit IgG antibodies as negative control and antibodies against acetylated $\mathrm{H} 3$ and $\mathrm{H} 3 \mathrm{~K} 9$ me 2 for detecting the histone acetlyation and methylation of genes, were added to the pre-cleared $2 \mathrm{ml}$ supernatant and incubated overnight at $4^{\circ} \mathrm{C}$ with constant rotation. Subsequently the protein A agarose/antibody/chromatin complex was washed using CHIP Washing Dilution (EMD Millipore) for 3-5 min with rotation. The The cross-links were reversed to recover the DNA for qPCR detection. The following primers were used for the Bcl-2 gene promoter: Forward 5'-CCAGTTGCTGCAGTTTGGAAT-3' and reverse 5'-TTGGACCATGTCTGGTGTCC-3'. The primer used for qPCR of the Bax gene promoter were: Forward 5'-ACGCTCCAGAATAACTGCC-3' and reverse 5'-GGTTTGCGCTGCGAGATAAG-3'. The qPCR reaction mixture contained 10 ng cDNA, 2x Taq PCR Green Mix (Dingguo Changsheng Co., Ltd., Beijing, China), $1 \mu$ l forward and reverse primers, and $\mathrm{H}_{2} \mathrm{O}$ to make upto a total volume of $25 \mu \mathrm{l}$. The PCR cycling conditions were set as follows: one cycle at $95^{\circ} \mathrm{C}$ for $5 \mathrm{~min}, 30$ cycles at $94^{\circ} \mathrm{C}$ for $45 \mathrm{sec}, 58^{\circ} \mathrm{C}$ for $45 \mathrm{sec}$ and $72^{\circ} \mathrm{C}$ for $60 \mathrm{sec}$, and then one cycle at $72^{\circ} \mathrm{C}$ for 6 min.

Statistical analysis. All data are expressed as the mean \pm standard deviation. Statistical analyses of data were performed using Student's t-test on SPSS version 17.0 (SPSS Inc., Chicago, IL, USA). $\mathrm{P}<0.05$ was considered to indicate a statistically significant difference.

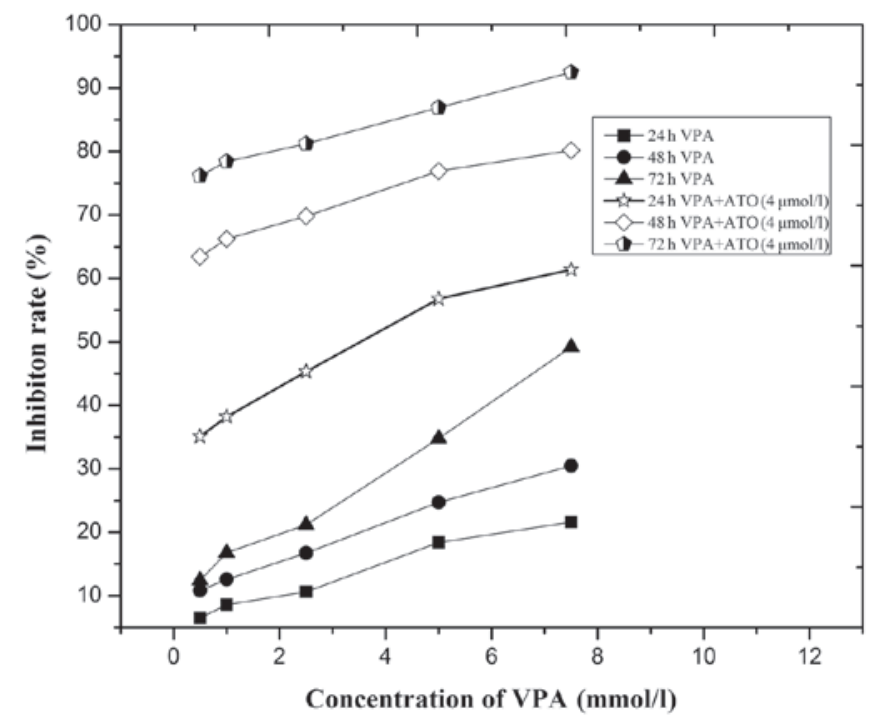

Figure 1. Time-dependent growth curve of the inhibition of VPA and ATO on the RPMI8226 cells, determined using a Cell Counting kit-8 assay. VPA, valproic acid; ATO, arsenic trioxide.

\section{Results}

Effects of VPA and/or ATO on the proliferation of RPMI8226 cells. In the preliminary experiment, VPA and ATO inhibited the proliferation of the RPMI8226 cells in a time- and dose-dependent manner. The combination of the two drugs had a synergistic effect with a Q-value $>1.15$. The growth rate of the RPMI8226 cells in the combined drug groups was significantly inhibited compared to those observed in the single drug groups $(\mathrm{P}<0.05$; Fig. 1).

Morphological observation. On examining the morphology of the RPMI8226 cells, the cells exhibited a decrease in number, with disordered arrangement, an increased number of cell fragments and increased cell apoptosis. These features were observed at a high magnification under an inverted fluorescent microscope (Fig. 2).

VPA and ATO treatment induces myeloma cell apoptosis. The present study also determined the percentage of apoptosis of the RPMI8226 cells following exposure to VPA, 

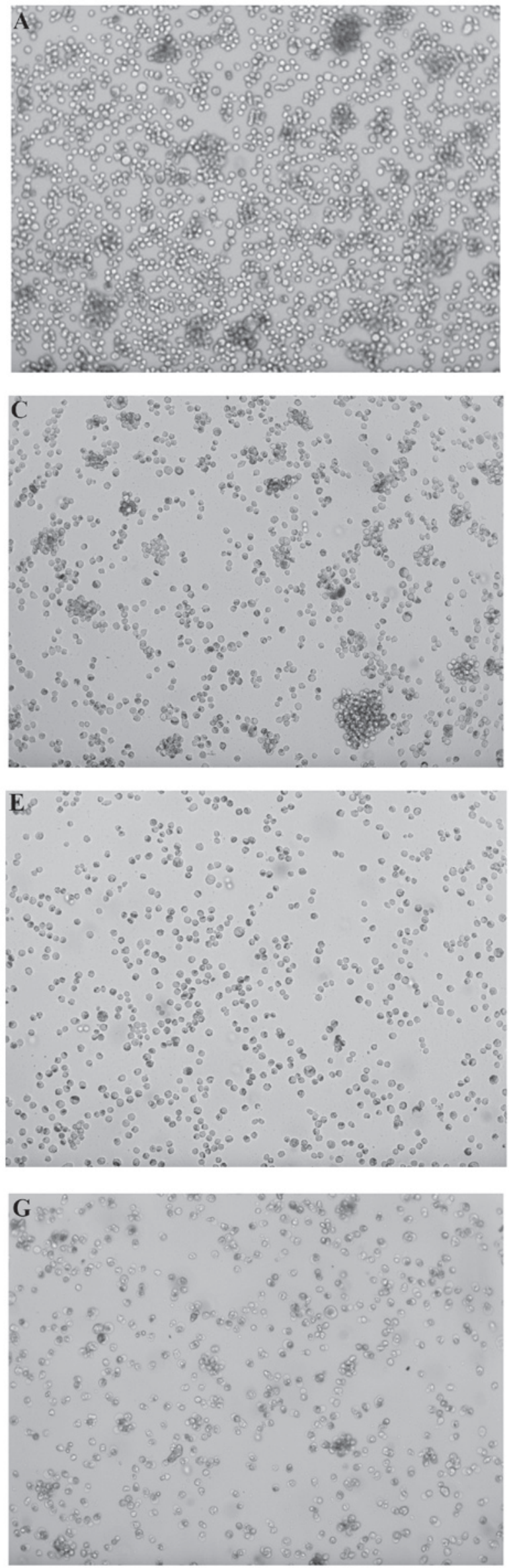
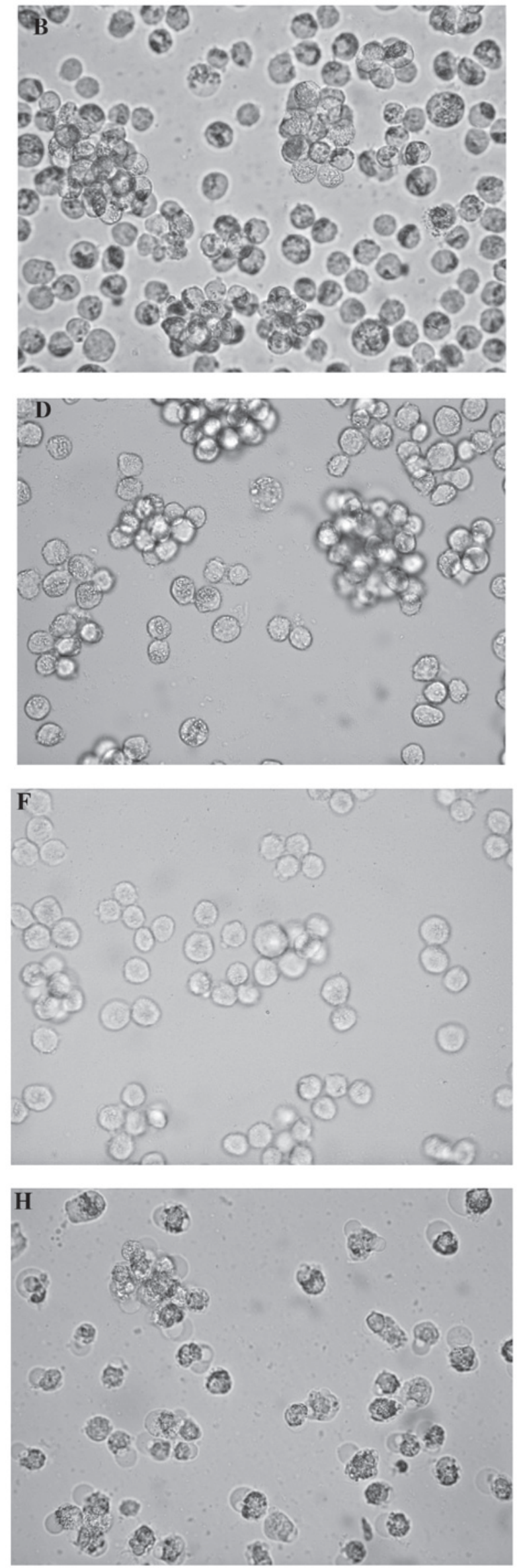

Figure 2. RPMI8226 cells cultured for $48 \mathrm{~h}$, viewed under an inverted fluorescent microscope. (A) Control group (magnification, x100), (B) control group (magnification, x400), (C) VPA 1 mmol/1 (magnification, x100), (D) VPA 1 mmol/l (magnification, x400), (E) VPA 5 mmol/l (magnification, x100), (F) VPA $5 \mathrm{mmol} / 1$ (magnification, $\mathrm{x} 400$ ), (G) ATO $4 \mu \mathrm{mol} / 1$ (magnification, x100), (H) ATO $4 \mu \mathrm{mol} / 1$ (magnification, x400). VPA, valproic acid; ATO, arsenic trioxide. 

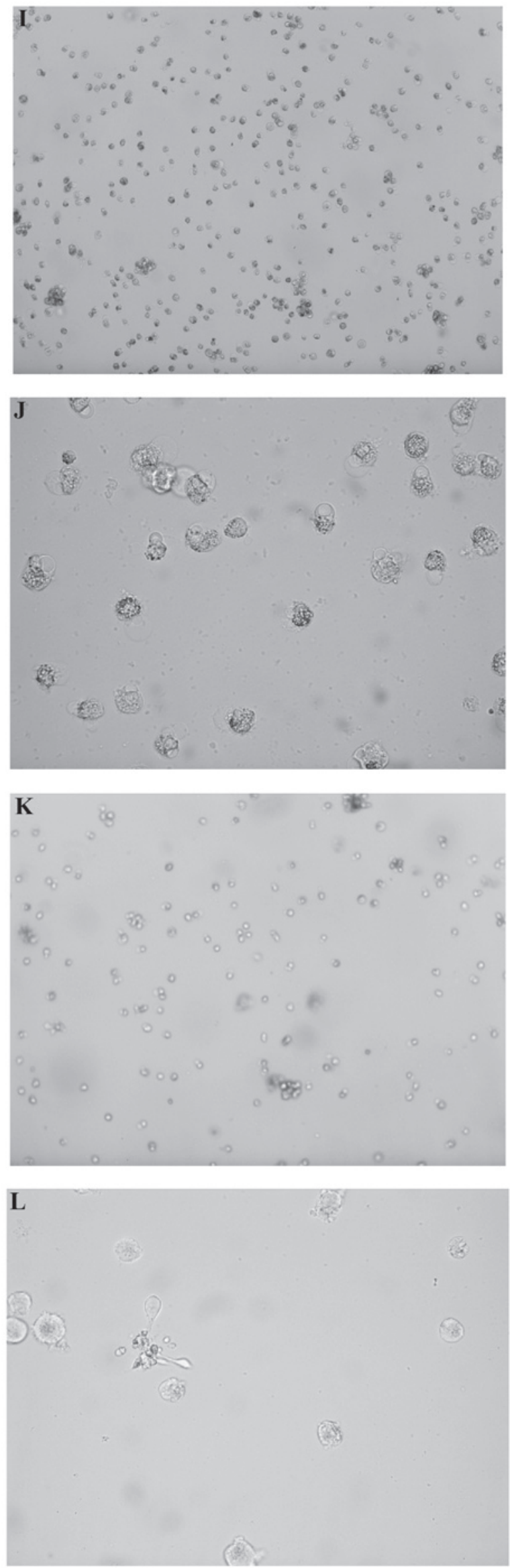

Figure 2. Continued. (I) VPA $1 \mathrm{mmol} / 1+\mathrm{ATO} 4 \mu \mathrm{mol} / 1$ (magnification, x100), (J) VPA $1 \mathrm{mmol} / 1+$ ATO $4 \mu \mathrm{mol} / 1$ (magnification, $\mathrm{x} 400$ ), (K) VPA $5 \mathrm{mmol} / 1+\mathrm{ATO} 4 \mu \mathrm{mol} / 1$ (magnification, $\mathrm{x} 100$ ), (L) VPA $5 \mathrm{mmol} / 1+\mathrm{ATO}$ $4 \mu \mathrm{mol} / 1$ (magnification, $\mathrm{x} 400$ ). VPA, valproic acid; ATO, arsenic trioxide.

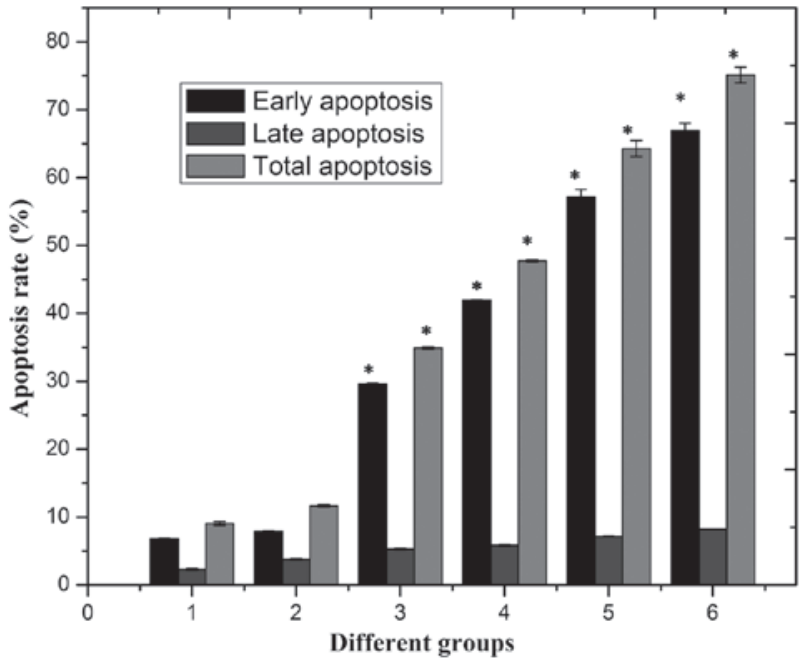

Figure 3. Assessment of apoptosis using flowcytometry with annexinV fluorescein isothiocyanate/propidium iodide staining. 1, control group; 2, VPA $1 \mathrm{mmol} / \mathrm{l} ; 3$, VPA $5 \mathrm{mmol} / 1$; 4 , ATO $4 \mu \mathrm{mol} / 1$; 5 , VPA $1 \mathrm{mmol} / 1+\mathrm{ATO}$ $4 \mu \mathrm{mol} / 1$; 6 , VPA $5 \mathrm{mmol} / 1+\mathrm{ATO} 4 \mu \mathrm{mol} / 1$. "P<0.05, vs. control. Data are expressed as the mean \pm standard deviation. VPA, valproic acid; ATO, arsenic trioxide.

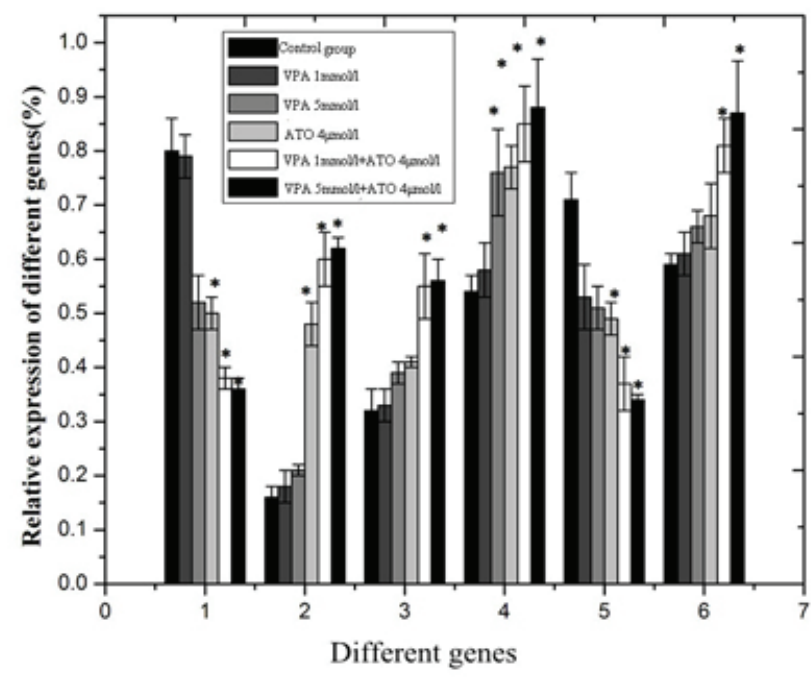

Figure 4. mRNA expression levels of Bax, Bcl-2, Caspase 8, Caspase 9, HDAC1 and LSD1 in the RPMI8226 cells: $1, A$ Bcl-2/ $\beta$-actin; $2, A B a x /$ $\beta$-actin; 3 , $A$ Caspase $8 / \beta$-actin; 4 , $A$ Caspase $9 / \beta$-actin; 5 , AHDAC1/ $\beta$-actin; 6 , ALSD1/ $\beta$-actin. " $\mathrm{P}<0.05$, vs. control. Data are expressed as the mean \pm standard deviation VPA, valproic acid; ATO, arsenic trioxide.

ATO, or the two combined, by flow cytometry using an annexin V FITC/PI assay (Fig. 5). The apoptotic rates of the RPMI8226 cells in the combined drug groups were significantly increased compared with those of the single drug groups ( $\mathrm{P}<0.05$; Fig. 3 ).

Increased mRNA expression levels of Bax, Caspase 8 and Caspase 9 and decreased $m R N A$ expression levels of Bcl-2 and HDACl. The mRNA expression levels of Bcl-2 and HDAC1 were significantly decreased, and the mRNA expression levels of Bax, Caspase 8 and Caspase 9 were significantly increased following exposure of the cells to VPA + ATO for 


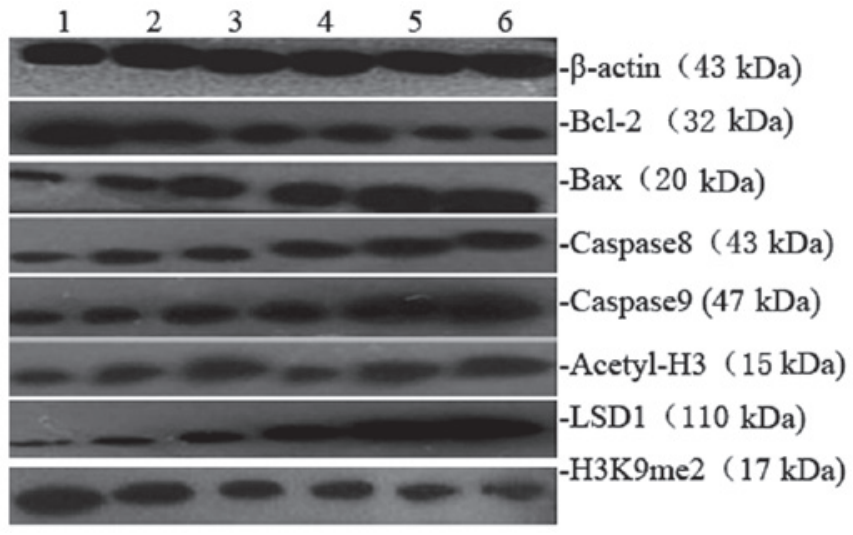

Figure 5. Protein expression levels of Bcl-2, Bax, Caspase 8, Caspase 9, acetylated H3, LSD1 and H3K9me2 in the RPMI8226 cells, analyzed by western blot analysis. 1, control group; 2, VPA $1 \mathrm{mmol} / 1$; 3, VPA $5 \mathrm{mmol} / 1$; 4 , ATO $4 \mu \mathrm{mol} / 1 ; 5$, VPA $1 \mathrm{mmol} / 1+\mathrm{ATO} 4 \mu \mathrm{mol} / \mathrm{l} ; 6$, VPA $5 \mathrm{mmol} / \mathrm{l}+\mathrm{ATO}$ $4 \mu \mathrm{mol} / 1$. VPA, valproic acid; ATO, arsenic trioxide.

\section{A}

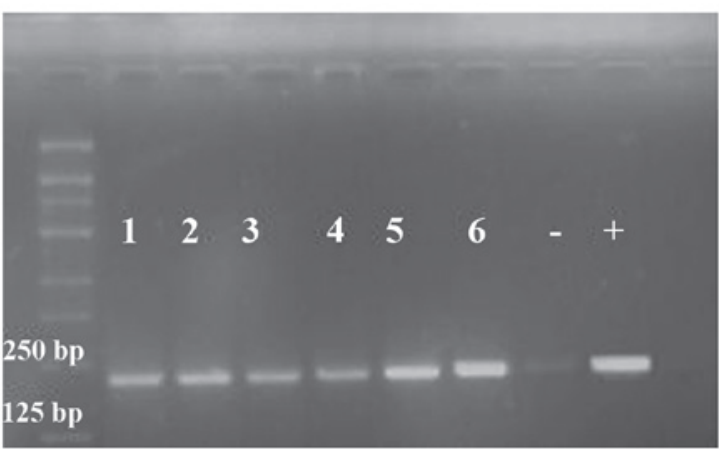

B

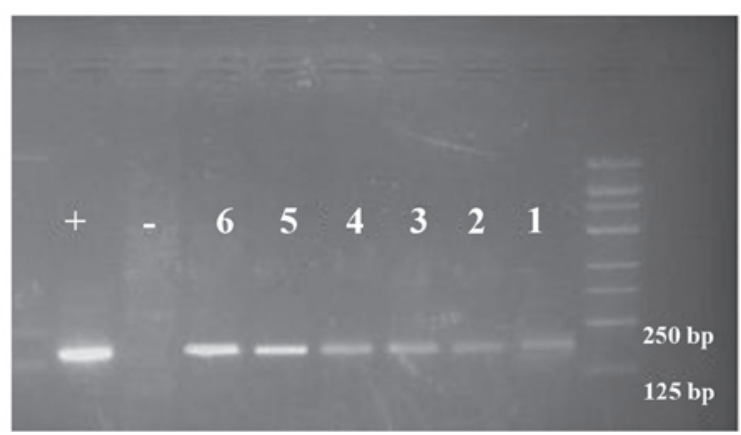

Figure 6. (A) Acetylation modification of the Bax gene promoter and (B) methylation modification of the Bcl-2 gene promoter in the RPMI8226 cells using a CHIP assay: 1, control group; 2, VPA $1 \mathrm{mmol} / \mathrm{l}$; 3, VPA $5 \mathrm{mmol} / \mathrm{l}$; 4, ATO $4 \mu \mathrm{mol} / 1$; 5, VPA $1 \mathrm{mmol} / 1+\mathrm{ATO} 4 \mu \mathrm{mol} / 1$; 6, VPA 5 mmol/1+ATO $4 \mu \mathrm{mol} / 1$. -, negative control (normal rabbit immunoglobulin $\mathrm{G}$ ); +, positive control (anti-RNA polymase antibody). VPA, valproic acid; ATO, arsenic trioxide.

$48 \mathrm{~h}$, compared with exposure to either of the drugs alone ( $\mathrm{P}<0.05$; Fig. 4).

Protein expression levels of Bcl-2, Bax, Caspase 8, Caspase 9, acetylated H3, LSD1 and H3K9me2 in RPMI 8226 cells with VPA, ATO, or combined treatment. The protein expression levels of Bcl-2 and $\mathrm{H} 3 \mathrm{~K} 9 \mathrm{me} 2$ were significantly decreased, and the protein expression levels of Bax, Caspase 8, Caspase 9 , acetylated $\mathrm{H} 3$ and LSD1 were significantly increased following exposure to VPA + ATO for $48 \mathrm{~h}$, compared with either of the drugs alone $(\mathrm{P}<0.05$; Fig. 5).
Histone acetylation and methylation state of the Bcl-2 and Bax gene promoters. The level of histone methylation of the Bcl-2 gene promoter and the level of acetylation of the Bax gene promoter were increased in the combination groups compared with the single drug groups (Fig. 6, Table I).

\section{Discussion}

MM is a B-cell malignancy, characterized by the accumulation of monoclonal plasma cells and the production of monoclonal immunoglobulin. Traditional chemotherapy and hematopoietic stem cell transplantation can extend the overall survival rates of patients with MM, however, almost all patients with MM eventually develop chemoresistance (2). The development of novel therapeutic options, including proteasome inhibitors and IMiDs, has improved treatment outcomes, however, patients often develop relapsed and refractory MM, thus requiring alternative treatment approaches. Histone acetyltransferases and histone deacetylases (HDACs) control the acetylation status of proteins and affect a broad array of physiologic processes involved in cell growth and survival, including cell cycle, apoptosis and protein folding (9). The observation that HDACs may be involved in various hematological malignancies, including MM, has led to the development of HDAC inhibitors (HDACIs) as potential antitumor agents. Several types of HDACI have been used to treat patients with MM in clinical trials, including vorinostat (SAHA) and panobinostat, however, the response is poor (11-13). The modest, yet encouraging, single-agent activity observed with HDAC inhibitors in heavily pretreated patients with MM has led to their evaluation in combination with other novel therapeutic agents (14-18). The clinical activity of HDAC inhibitors in combination with proteasome inhibitors, IMiDs and conventional cytotoxic agents has been demonstrated in heavily pretreated MM patients, supporting the continued evaluation of these regimens in this patient population (19). VPA is a well-tolerated anticonvulsant, which exerts antitumor activity as a histone deacetylase inhibitor. In vitro exposure of interleukin-6-dependent or -independent MM cells to VPA inhibits cell proliferation in a time- and dose-dependent manner and induces apoptosis (20). In a cohort of severe combined immunodeficienct mice bearing human MM xenografts, VPA was observed to induce tumor growth inhibition and improve survival rates in treated animals compared with controls (20).

ATO has long been used as a therapeutic agent. It was first used to treat acute promyelocytic leukemia and has been suggested as an option for the treatment of relapsing or refractory multiple myeloma (21). Monotherapy with ATO results in partial response rates between 0 and $17 \%$ and minimal response rates of $7-33 \%$, resulting in a mean overall response rate of $30 \%(22,23)$. Previously, the combination of ATO with ascorbic acid, dexamethasone, bortezomib or thalidomide have been used to treat patients with refractory or relapsed MM. The overall response rates of using ATO in addition to dexamethasone, melphalan or other cytostatic agents varies considerably, between $12-100 \%$. Complete remission has been achieved in the minority of cases (0-25\%). The duration of response in previous studies has also varied, ranging between 0 and 24 months (24-28). Therefore, it is necessary to identify novel therapeutic combinations. 
It has been reported that VPA combined with ATO induces the apoptosis of HL-60 and K562 cells (29). In the present study, VPA and ATO inhibited the proliferation of the RPMI8226 cells. The combination of the two drugs had a synergistic effect (Q-value $>1.15$ ). The apoptotic rate of the RPMI8226 cells in the combined drug group ( $5 \mathrm{mmol} / 1 \mathrm{VPA}+4 \mu \mathrm{mol} / \mathrm{l}$ ATO $)$ was $75.11 \pm 1.16 \%$. The apoptotic rate of the RPMI8226 cells in the $5 \mathrm{mmol} / \mathrm{l} \mathrm{VPA}$ and $4 \mu \mathrm{mol} / \mathrm{l}$ ATO single drug group was $11.65 \pm 0.20 \%$ and $47.74 \pm 0.18 \%$, respectively. In addition, the mRNA and protein expression levels of Caspase 8 and Caspase 9 increased in the combination groups compared with the single drug groups. The expression of $\mathrm{Bcl}-2$ was decreased and the expression of Bax was increased following combined treatment with VPA and ATO. Therefore, it was hypothesized that VPA combined with ATO induced the apoptosis of MM cells through the intrinsic and extrinsic apoptotic pathway.

VPA, as a histone deacetylase inhibitor can increase histone acetylation levels. Previous studies have demonstrated that ATO can combine with protein-rich cysteine or contain thiol to exert antitumor effects (30). Histone deacetylase, which contains cysteine readily combines with ATO. It has been observed that ATO inhibits the expression of histone acetyltransferase 6 in the NCI-H929 myeloma cell line and primary myeloma cells (30). In the present study, the mRNA expression level of HDAC1 decreased, and the mRNA expression level of LSD1 increased, therefore, the protein expression levels of acetylated $\mathrm{H} 3$ and $\mathrm{H} 3 \mathrm{~K} 9 \mathrm{me} 2$ increased significantly following exposure to VPA combined with ATO for $48 \mathrm{~h}$, compared with the single drug groups $(\mathrm{P}<0.05)$. VPA and ATO may, therefore, coordinately regulate histone acetylation and methylation.

Epigenetic changes, including histone modification is correlated with cells apoptosis (31). In the present study, the histone acetylation and methylation state of the Bcl-2 and Bax gene promoters were detected by chromatin immunoprecipitation. The methylation level of the Bcl-2 gene promotor and acetylation level of the Bax gene promoter were both increased. Histone acetylation activated the transcription of certain genes and methylation inhibited the transcription of several genes, therefore, the expression levels of the Bcl-2 gene family may be regulated by the methylation and acetylation levels of the Bcl-2 and Bax gene promoters, and involved in the apoptosis of RPMI 8226 cells. In order to provide an evidence-based basis for the clinical application of VPA combined with ATO for the treatment of MM, further investigation is required to determine whether other mechanisms of apoptosis in RPMI8226 cells are induced by VPA and ATO.

\section{Acknowledgements}

The authors would like to thank Dr Jing Li, Dr Meiyin Qi and Dr Yue Teng for their technical assistance.

\section{References}

1. He X, Yang K, Chen P, et al: Arsenic trioxide-based therapy in relapsed/refractory multiple myeloma patients: A meta-analysis and systematic review. Onco Targets Ther 7: 1593-1599, 2014.

2. Spitzer TR, Sachs DH and Cosimi B: Multiple myeloma. N Engl J Med 364: 2364, 2011

3. Hussein MA, Saleh M, Ravandi F, et al: Phase 2 study of arsenic trioxide in patients with relapsed or refractory multiple myeloma. Br J Haematol 125: 470-476, 2004.
4. Sanaat Z, Rezazadeh M, Gharamaleki JV, et al: Arsenic trioxide in patients with refractory multiple myeloma: A prospective, phase II, single-arm study. Acta Med Iran 49: 504-508, 2011.

5. Rousselot P, Larghero J, Arnulf B, et al: A clinical and pharmacological study of arsenic trioxide in advanced multiple myeloma patients. Leukemia 9: 1518-1521, 2004.

6. Wu K, van Droogenbroeck J, Beksac M, et al: Treatment with asenic trioxide, ascorbic acid and dexamethasone in advanced myeloma patients: Preliminary findings of a multicenter, phase II study. Blood 106: 367b, 2005 .

7. Berenson JR, Boccia R, Siegel D, et al: Efficacy and safety of melphalan, arsenic trioxide and ascorbic acid combination therapy in patients with relapsed or refractory multiple myeloma: A prospective, multicentre, phase II, single-arm study. Br J Haematol 135: 174-183, 2006.

8. Bertenson J, Marous J, Ferretti D, et al: A phase I/II trial evaluation the combination of arsenic trioxide, bortezomib and ascorbic acid for patients with relapsed or refractory multiple myeloma. Blood 106: 2565, 2005.

9. Matthews GM, Newbold A and Johnstone RW: Intrinsic and extrinsic apoptotic pathway signaling as determinants of histone deacetylase inhibitor antitumor activity. Adv Cancer Res 116: 165-197, 2012.

10. Ye BG, Lin FA, Shen JZ, et al: Synergistic effects of VPA and $\mathrm{As}_{2} \mathrm{O}_{3}$ on Molt- 4 cells in vitro and its possible mechanisms. Zhongguo shi yan xue ye xue za zhi 16: 1288-1292, 2008.

11. Dimopoulos M, Siegel DS, Lonial S, et al: Vorinostat or placebo in combination with bortezomib in patients with multiple myeloma (VANTAGE 088): a multicentre, randomised, double-blind study. Lancet Oncol 14: 1129-1140, 2013.

12. Wang M, Martin T, Bensinger W, et al: Phase 2 dose-expansion study (PX-171-006) of carfilzomib, lenalidomide and low-dose dexamethasone in relapsed or progressive multiple myeloma. Blood 122: 3122-3128, 2013.

13. Kaufman JL, Fabre C, Lonial S, et al: Histone Deacetylase Inhibitors in Multiple Myeloma: Rationale and Evidence for Their Use in Combination Therapy. Clin Lymphoma Myeloma Leuk 13: 370-376, 2013

14. Richardson P, Mitsiades C, Colson K, et al: Phase I trial of oral vorinostat (suberoylanilide hydroxamic acid, SAHA) in patients with advanced multiple myeloma. Leuk Lymphoma 49: 502-507, 2008.

15. Galli M, Salmoiraghi S, Golay J, et al: A phase II multiple dose clinical trial of histone deacetylase inhibitor ITF2357 in patients with relapsed or progressive multiple myeloma. Ann Hematol 89: 185-190, 2010

16. Niesvizky R, Ely S, Mark T, et al: Phase 2 trial of the histone deacetylase inhibitor romidepsin for the treatment of refractory multiple myeloma. Cancer 117: 336-342, 2011.

17. DeAngelo DJ, Spencer A, Bhalla KN, et al: Phase Ia/II, two-arm, open-label, dose-escalation study of oral panobinostat administered via two dosing schedules in patients with advanced hematologic malignancies. Leukemia 27: 1628-1636, 2013.

18. Gimsing P, Hansen M, Knudsen LM, et al: A phase I clinical trial of the histone deacetylase inhibitor belinostat in patients with advanced hematological neoplasia. Eur J Haematol 81: 170-176, 2008.

19. Richardson PG, Mitsiades CS, Laubach JP, et al: Preclinical data and early clinical experience supporting the use of histone deacetylase inhibitors in multiple myeloma. Leuk Res 37: 829-837, 2013.

20. Neri P, Tagliaferri P, Di Martino MT, et al: In vivo anti-myeloma activity and modulation of gene expression profile induced by valproic acid, a histone deacetylase inhibitor. Br J Haematol 143: 520-531, 2008

21. Lengfelder E, Hofmann WK and Nowak D: Treatment of acute promyelocytic leukemia with arsenic trioxide: Clinical results and open questions. Expert Rev Anticancer Ther 13: 1035-1043, 2013.

22. Berenson JR and Yeh HS: Arsenic compounds in the treatment of multiple Myeloma: A new role for a historical remedy. Clin Lymphoma Myeloma 7: 192-198, 2006.

23. Sanaat Z, Rezazadeh M, Gharamaleki JV, et al: Arsenic trioxide in patients with refractory multiple myeloma: A prospective, phase II, single-arm study. Acta Med Iran 49: 504-508, 2011.

24. Held LA, Rizzieri D, Long GD, et al: A Phase I study of arsenic trioxide (Trisenox), ascorbic acid and bortezomib (Velcade) combination therapy in patients with relapsed/refractory multiple myeloma. Cancer Invest 31: 172-176, 2013. 
25. Sanaat Z, Rezazadeh M, Gharamaleki JV, et al: Arsenic trioxide in patients with refractory multiple myeloma: a prospective, phase II, single-arm study. Acta Med Iran 49: 504-508, 2011.

26. Sharma M, Khan H, Thall PF, et al: A randomized phase 2 tria of a preparative regimen of bortezomib, high-dose melphalan, arsenic trioxide and ascorbic acid. Cancer 118: 2507-2515, 2012.

27. Takahashi S: Combination therapy with arsenic trioxide for hematological malignancies. Anticancer Agents Med Chem 10: 504-510, 2010.

28. Röllig C and Illmer T: The efficacy of arsenic trioxide for the treatment of relapsed and refractory multiple myeloma: a systematic review. Cancer Treat Rev 35: 425-430, 2009.
29. Peng CY, Jiang J, Zheng HT, et al: Growth-inhibiting effects of arsenic trioxide plus epigenetic therapeutic agents on leukemia cell lines. Leuk Lymphoma 51: 297-303, 2010.

30. Qu X, Du J, Zhang C, et al: Arsenic trioxide exerts antimyeloma effects by inhibiting activity in the cytoplasmic substrates of histone deacetylase 6. PLoSOne 7: e32215, 2012.

31. Selokar NL, St John L, Revay T, et al: Effect of histone Deacetylase inhibitor Valproic acid treatment on donor cell growth characteristics, cell cycle arrest, apoptosis and handmade cloned Bovine Embryo production efficiency. Cell Reprogram 15: $531-542,2013$. 